\title{
Ranger based monitoring in the Virunga-Bwindi region of East-Central Africa: a simple data collection tool for park management
}

\author{
MARYKE GRAY* and JOSÉ KALPERS \\ International Gorilla Conservation Programme, BP 931 Kigali, Rwanda; *Author for correspondence \\ (e-mail: marykegray@compuserve.com)
}

Received 5 April 2004; accepted in revised form 10 October 2004

Key words: Bwindi Impenetrable National Park, Locally-based monitoring, Mountain gorilla conservation, Protected area management, Ranger-based monitoring, Virunga Massif

\begin{abstract}
Effective management of protected areas is dependent on information on the illegal and legal use of the habitat by people, the ecological and behavioural needs of key species, and trends in resource availability and ecological processes. The International Gorilla Conservation Programme working with the protected area authorities in Rwanda, Uganda and the Democratic Republic of Congo has developed a ranger based monitoring system, using basic protocols for data collection that guide protected area staff in park management. This programme is a key management tool for the three park authorities responsible for the conservation of the mountain gorilla (Gorilla beringei beringei) in the Virunga and Bwindi forest blocks. The programme was initiated in 1997 and has enabled the gathering of extensive information on illegal activities, key species of fauna and flora, and habituated and unhabituated groups of gorillas. Ranger based monitoring is a simple and cost effective tool that can be sustained in the parks in the Virunga-Bwindi region with limited external support. It provides park managers with information that prompts appropriate responses to threats to the ecosystem. For example information on the distribution of illegal activities determines targeted patrol coverage to address specific threats. The bottom-up approach of ranger based monitoring includes a strong capacity building component and empowers field staff in park management activities.
\end{abstract}

\section{Introduction}

Protected areas play an extremely important role in conservation because they often represent the only viable reservoirs of biodiversity. Human population pressure is having an increasingly serious effect on natural resources, above all in developing countries where agriculture, with an ever increasing demand for land, is the most important means of subsistence. Therefore we must pay particular attention to long-term conservation of protected areas and to orient our priorities towards efficient management and well-planned activities.

Monitoring is designed to reveal long-term changes - or the absence of change - at the heart of ecosystems and their component communities. The observation and analysis of these changes is necessary in order to gain a basic understanding of natural areas, in order to ensure coherent and effective 
conservation programmes. When applied to natural ecosystems, 'monitoring' (or 'ecological monitoring') is a necessary tool on which managers should base many of their conservation actions. Monitoring can cover a multitude of different types of data. Amongst all the possibilities, choices must be made to streamline data collection efforts in relation to the needs and the management objectives of the particular protected area (Liebenberg 2003). While conventional statistical methods offer a reliable way to test data sets, it is necessary to first ask what type of information is required for management purposes. In fact, often management decisions (for surveillance, tourism, etc.) don't require statistically significant results (Sheil 2001). Park managers need a steady flow of information which is delivered without disruption, and a management decision can often be taken based on a less scientifically rigorous approach.

A number of constraints also face protected area managers in developing countries, which impact on their ability to implement monitoring programmes. These include the lack of both human and financial resources, and may also include war or political instability. These constraints mean that most protected areas can't afford a full time, long-term ecological monitoring programme that uses a scientific approach with rigorous systematic sampling. Park managers are often left with two options: ignore monitoring and data collection, or incorporate this aspect into the daily work of their field staff. The latter option can only work in the long term if; (a) the system is used in a simplistic way; (b) the amount of information collected is confined to key species, habitats, threats and values; (c) a balance between technology and sustainability can be found.

As resources for nature conservation are likely to remain scarce in developing countries, a flexible range of methods needs to be developed, as priorities and circumstances alter. We therefore need to look for systems that do not consume large quantities of resources and are easily adaptable in times of conflict. In 1997, the International Gorilla Conservation Programme (IGCP, a coalition of Fauna and Flora International, the World Wide Fund for Nature, and the African Wildlife Foundation) developed a ranger based monitoring (RBM) programme as a key management tool for the three park authorities responsible for the conservation of the mountain gorilla (Gorilla beringei beringei) in the Virunga and Bwindi forest blocks of Rwanda, Uganda and the Democratic Republic of Congo.

To illustrate the potential value of the RBM programme for park management and conservation, in this paper we present a selection of examples of the data collected to date and their application to protected area management.

\section{Methods}

\section{Area of interest}

The Virunga-Bwindi region has extremely high human population pressures with an average of 300 people per square kilometre (Lanjouw et al. 2001), with 
some rural areas attaining 820 people per square kilometre (Waller 1996). The average population growth rate in this region exceeds 3\% (IGCP 1996). The area has been periodically affected by political instability and war over the last 15 years. Rwanda and Uganda are each at different stages of emerging from prolonged periods of crisis, while the Democratic Republic of Congo (DRC) is going through a fragile period of post-war transition. More than $90 \%$ of the people conduct a subsistence agricultural lifestyle and many depend on resources from the protected areas to supplement their livelihoods. The majority of the human population in this region has been classified as living in extreme poverty, with more than $50 \%$ lacking sufficient land to meet their basic needs (Lanjouw et al. 2001).

Bwindi Impenetrable National Park (BINP) and the Virunga Massif lie within the Central Albertine Rift region (Figure 1). These two forest blocks contain high and medium altitude forest, spanning the borders of Rwanda, Uganda and DRC. The region has a high level of annual rainfall and an altitudinal range from $1100 \mathrm{~m}$ to $4511 \mathrm{~m}$. These parks support a combination of high species richness, a high proportion of endemic species and significant numbers of rare and threatened wildlife. These features have ranked the afromontane forests of the Albertine Rift as the highest priority for the conservation of restricted range animal species in Africa (Hamilton 1996; Brooks et al. 2001; Plumptre et al. 2003). These forested parks are also home to the mountain gorillas and their existence is jeopardized by the threats to the forest. Effective conservation of the gorillas is contingent upon the effective management and protection of their habitat. Afromontane vegetation also provides more water to streams than it loses through evapo-transpiration and thus the forested slopes of the Virunga Massif and BINP provide an important water catchment area. For example, it is estimated that the $0.6 \%$ of the land surface represented in Parc National des Volcans (PNV) provides 10\% of the watercatchment function for Rwanda (Weber 1987). The forests also curb soil erosion and flooding in the region and maintain dry season stream flow and local climates (Lanjouw et al. 2001).

\section{History and development}

Baseline data on the area has traditionally been collected by scientists in a discontinuous way, and has not always been available to the park management staff. Scientific methods are often costly, consume large quantities of resources (both financial and human) and research topics are usually not chosen by the protected area authorities and so are not always providing information that is needed for park management.

The RBM programme was developed in 1997 due to the realization that despite two decades of regular gorilla tracking for tourism purposes, very little information was available on the tourist gorilla groups. Likewise, there was no long-term data on aspects such as illegal activities in the Virunga Massif, or 


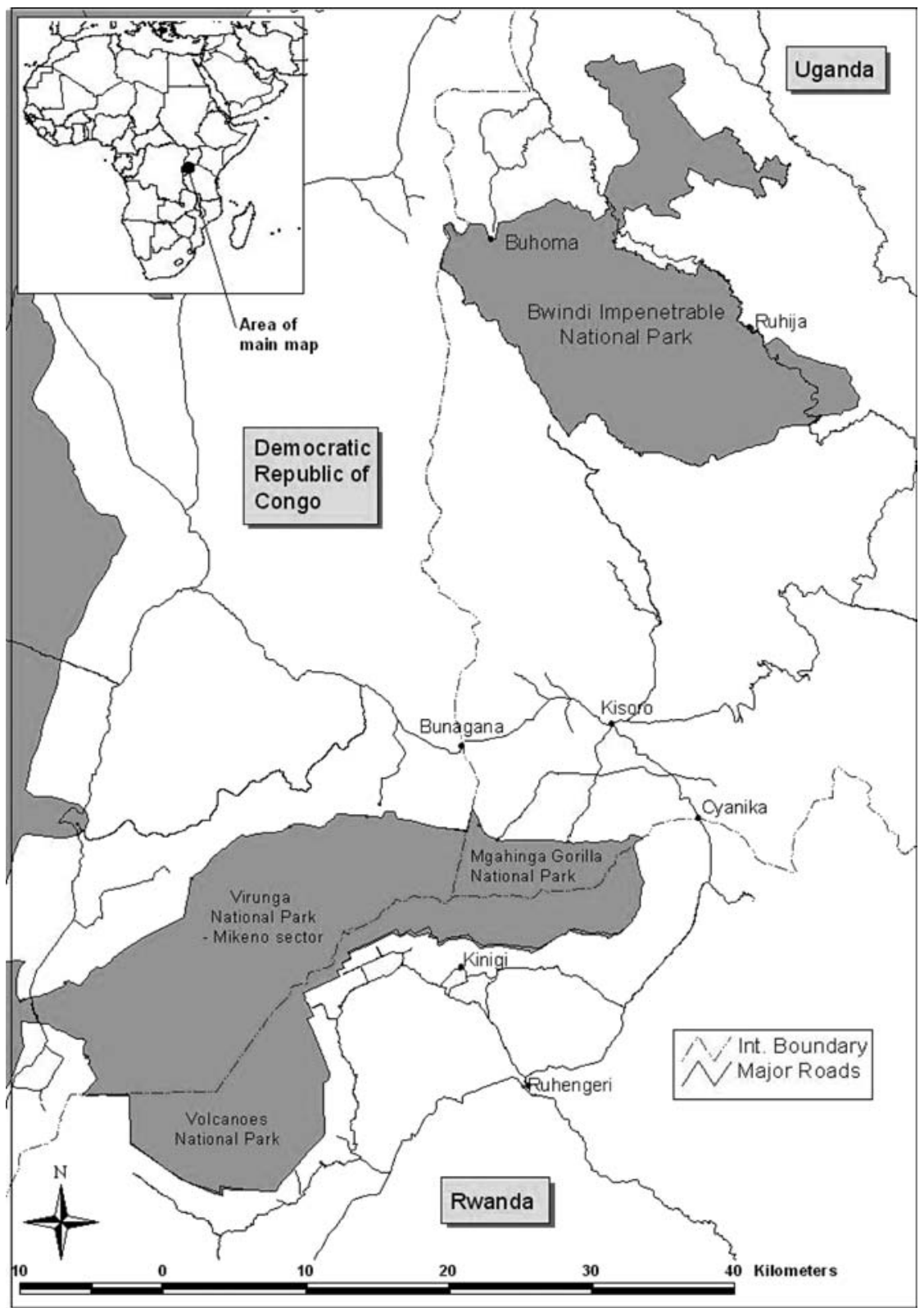

Figure 1. Location of the study area in the Virunga-Bwindi Region of East-Central Africa.

observations of key species of fauna. Until then, patrol records were sporadic and disorganized and not presented to park managers in a clear and meaningful way. 
Ranger-based monitoring is in the first place a tool for conservation of mountain gorillas and their habitat. IGCP working with the protected area authorities in the three countries (Uganda Wildlife Authority (UWA), Office Rwandais du Tourisme et des Parcs Nationaux (ORTPN), and Institut Congolais pour la Conservation de la Nature (ICCN)), has developed simple protocols to enable protected area staff to collect data that would help guide them in their management of the park. The objective of the programme is to 'provide a basic tool for ecosystem surveillance and management in the Virungas and Bwindi Forest ecosystem'. The programme is known as the RBM programme due to its emphasis on data collection and routine monitoring conducted by park staff on daily patrols, and use of this information for dayto-day management and conservation. The main features of RBM are:

- a system making full use of the presence of rangers, trackers and guides in the forest, without increasing their workload;

- a system for data collection in a systematic and organized way;

- a system using basic observations, that aims to detect broad trends within the ecosystem and/or key species.

The programme is currently applied in each of the four parks where mountain gorillas are found. It was established in Parc National des Virunga (DRC) in 1997, Parc National des Volcans (Rwanda) and Mgahinga Gorilla National Park (Uganda) in 1998, and Bwindi Impenetrable National Park (Uganda) in 1999. In the two mountain gorilla parks in Uganda, RBM was developed in collaboration with the German cooperation (GTZ) which established a nation wide monitoring system for the national park network.

\section{Tools}

Training tools developed for RBM include reference materials: a catalogue of toponyms (geo-referenced local place names), a database for the habituated gorillas, basic maps (topographic/toponymic maps and a satellite mosaic of the region), and the production of monitoring manuals in several languages.

Data collection uses a standardized data sheet that is systematically filled out by patrol rangers on routine patrols and also a gorilla data sheet that is filled out with every visit to the habituated groups of gorillas. Observations of key species of flora and fauna, human activities, and habituated gorilla groups are located using a system of toponyms. The Global Positioning System (GPS) is also used to gather more specific geo-referenced data on the daily locations of the gorilla groups to enable the park staff to calculate the most accurate home ranges for each group.

In order to implement the programme IGCP has organized the training of 'trainers' (staff members from the protected area authorities in the three countries), who now operate as the park-based monitoring units. Monitoring 
supervisors train field team leaders who then train field teams. With this approach ultimately all park staff are trained in monitoring techniques. Each country has its own monitoring unit composed of rangers who do the daily data collection and senior staff who supervise the programme and compile the data into monthly reports and field maps. The data are also plotted spatially using the Geographical Information System (GIS) developed for the region. The summaries and maps are presented each month to the Chief Wardens of the 4 parks, who can then take the appropriate management decisions. The monthly data are analysed to determine the levels of threats to the ecosystem, and also observations of large mammals. This is then used for a comparison between months and also between years, to look at longer term trends.

Analysis of RBM data includes calculating the relationship between the observations (illegal activities, key species of fauna and flora) recorded on patrol and the patrol effort. For each park, quantification of patrol effort uses patrol man-days per unit time. The total for each type of observation is divided by the number of man-days on patrol to give an index of encounter rate of each type of observation per patrol man-day per unit time, which is one month or one year.

In addition, the summaries are incorporated into the monthly park reports that are sent to the headquarters of each of the protected area authorities and then incorporated into national level monitoring in each country.

\section{Results}

Despite the challenges, the 7 years of RBM have yielded definite achievements. Table 1 presents some key activities that illustrate programme performance. A monitoring unit is functional in each park with a total of 157 patrol rangers trained. A total of 315 gorillas have been identified, referenced and included in the gorilla database for the region, and 1520 toponyms have been geo-referenced (Figure 2).

The managers of the four protected areas containing mountain gorillas use the results from the RBM programme in order to make information-based decisions on at least four levels:

1) Surveillance: The applied surveillance methods can guide, in real-time, law-enforcement efforts. The programme provides updated information on the observations of illegal activities and hence where to send patrols. Data are also analysed over time to look at whether particular threats are linked to certain seasons. Figure 3 shows bamboo cutting, water collecting and antelope snares, three of the main threats to conservation of the Virunga Massif, across different seasons (dry season is June to August, the wet season is all other months). Data are also analysed to look at changes through time, between months and between years, with both the total number of illegal activities and also specific illegal activities. Figure 4 shows the total number of illegal activities from 2000 to 2003, and Figure 5 shows the number of antelope snares 


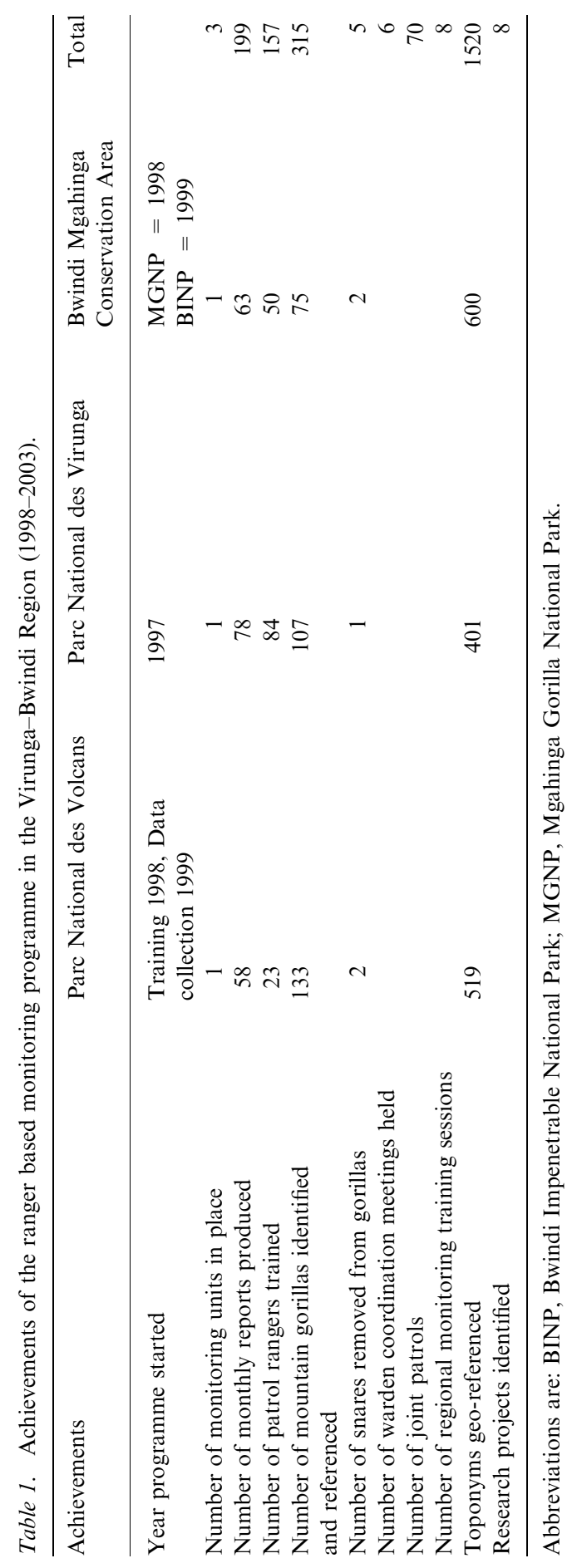




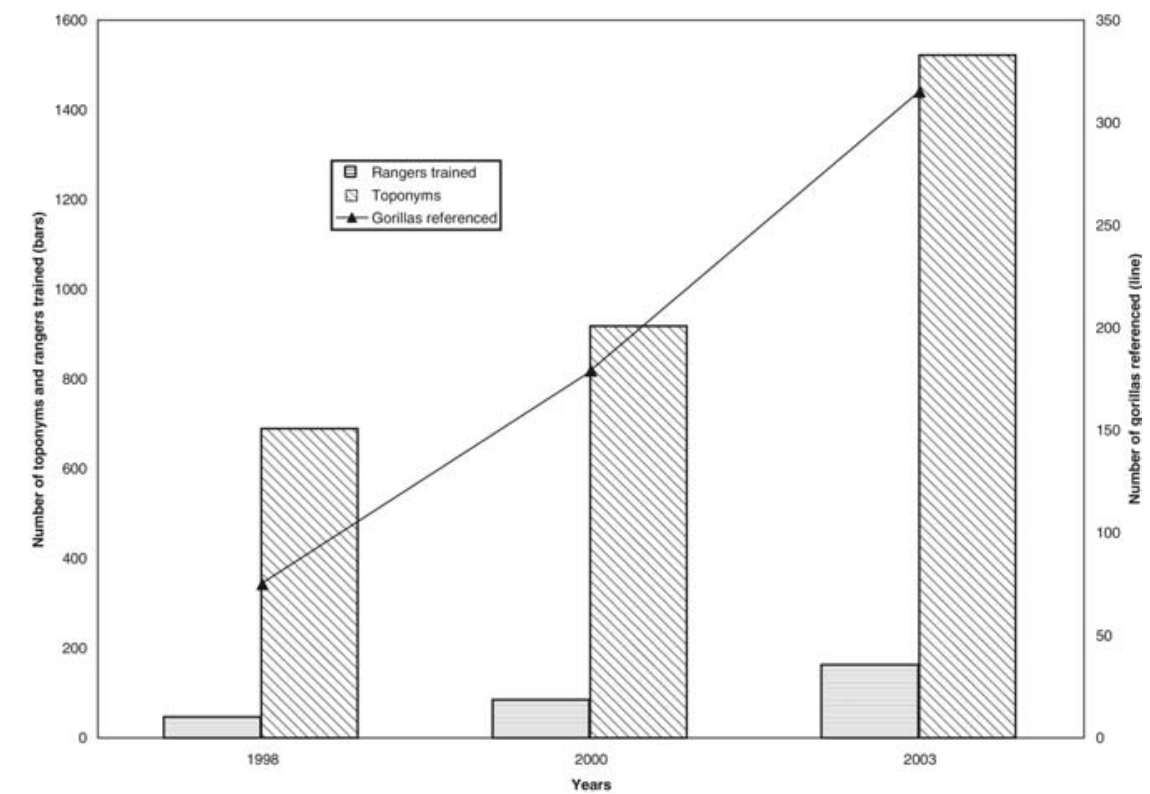

Figure 2. Achievements of the ranger based monitoring programme in the Virunga-Bwindi Region (1998-2003).

and bamboo cutting over the same period of time. The mean number of man days on patrol per year was also calculated and over the 4 year period (20002003) results indicate that there has been a significant increase in patrol effort (ANOVA: $F=42, d f=3, p<0.001$ ).

Links are being made between threats to the forest and the resource use and socio-economic conditions in the surrounding communities. Figure 6 shows the location of water collecting inside the forest (RBM data) combined with the results of a socio-economic study showing the levels of dependency of the community outside the forest on collecting water from inside (Plumptre et al. 2004).

Monthly maps of gorilla home ranges are plotted together with the monthly illegal activities to illustrate to park managers the threats that the different gorilla groups are being exposed to (Figure 7). In this example (July 2003), there were few threats close to the habituated gorillas in DRC. In Rwanda and Uganda illegal activities recorded in the gorilla home ranges included cattle grazing, water collecting, antelope snares and bamboo cutting.

2) Tourism: Information on annual gorilla group home ranges, daily gorilla locations or seasonal use of habitat can also help management decisions related to tourism. Figure 8 shows the home ranges for the tourism gorilla groups in September 2003 illustrating the distribution of the different groups across the Virunga Massif, the amount of overlap between groups (particularly in DRC) and the trans-boundary nature of the gorillas. 


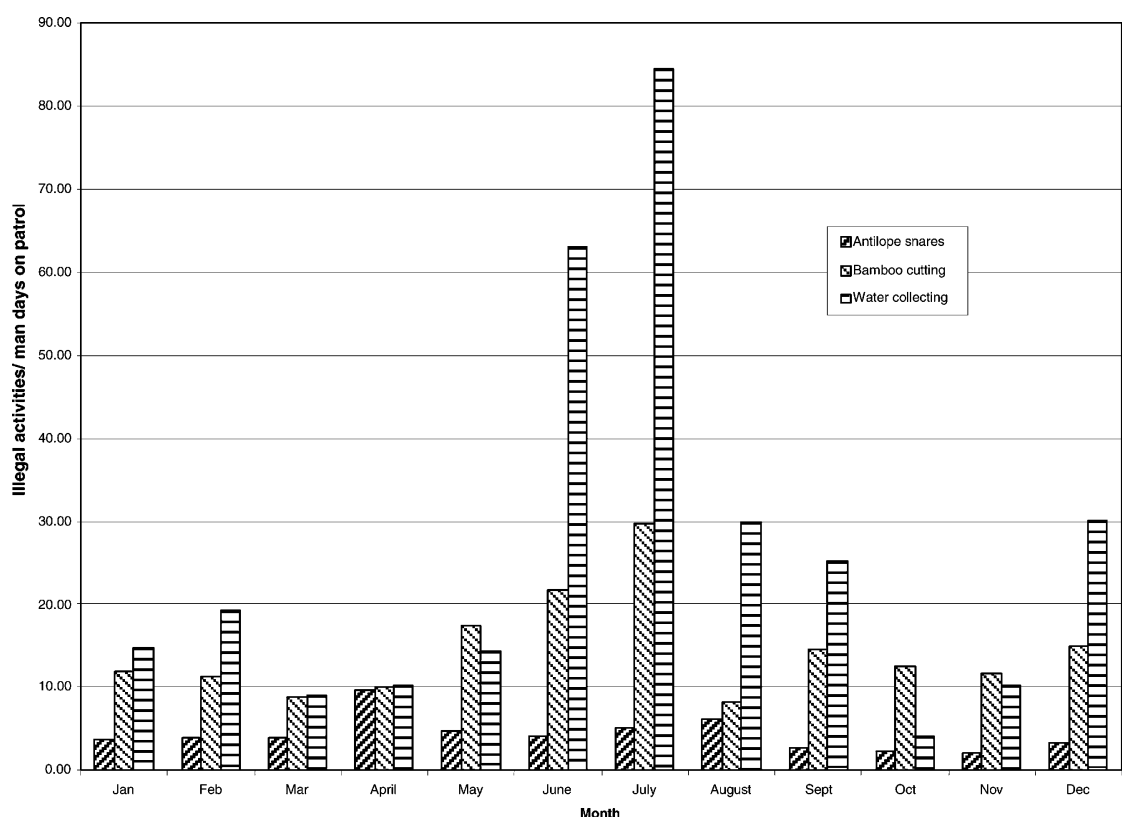

Figure 3. Number of observations of illegal activities (antelope snares, bamboo cutting, and water collecting) per man days on patrol across different seasons in the Virunga Massif (dry season $=$ June-August).

3) Gorilla ecology (population dynamics, ranging and feeding ecology) and behaviour: An up-to-date database on all habituated gorillas has been created, giving an up-to-date insight into gorilla dynamics and ecology over the whole ecosystem. The monitoring programme provides regular data documenting the impact of human activities such as tourism on gorilla populations and can be used to assist in taking decisions such as habituating more groups or stopping habituation. It also provides an early warning system for any potential health problems as the guides and trackers check on the physical condition of all individuals, leading to veterinary interventions in emergency situations (Kalpers et al. 2003). Table 2 illustrates the number of gorilla injuries/amputations pre and post the RBM programme. Prior to RBM, information being collected on the gorillas was sporadic and it was often days or weeks before it was noticed that a gorilla was missing, injured or had a snare on a limb. Consequently a total of 15 gorillas in the tourism groups had lost a limb as a result of a snare. Once RBM was established close monitoring of individual gorillas resulted in much faster responses in cases of injured gorillas. Since 1998 only two gorillas have lost limbs as a result of a snare.

4) Regional protected area management: The International Gorilla Conservation Programme regularly assists park authorities to implement joint patrols along the international boundaries of the parks: these patrols strengthen the regional linkages as well as provides a valuable law enforcement 


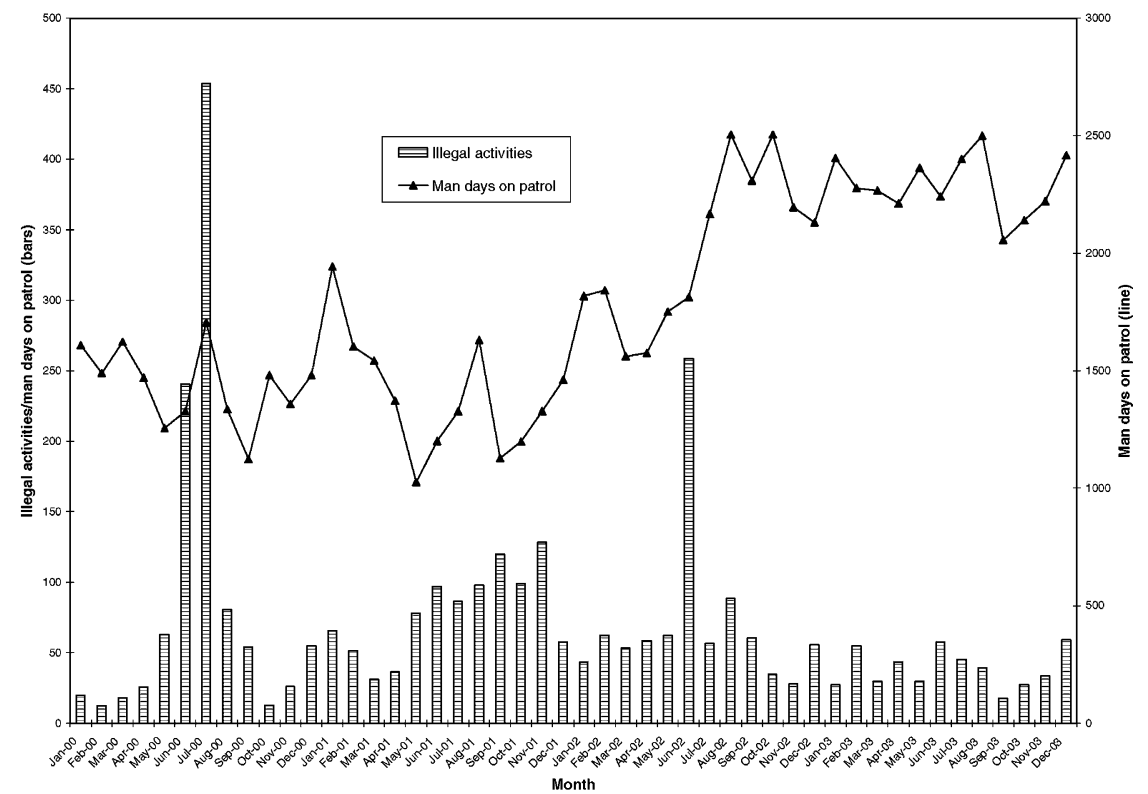

Figure 4. Number of observations of illegal activities per man days on patrol (bars), and effort (line; number of man days on patrol) in the Virunga Massif, 2000-2003.

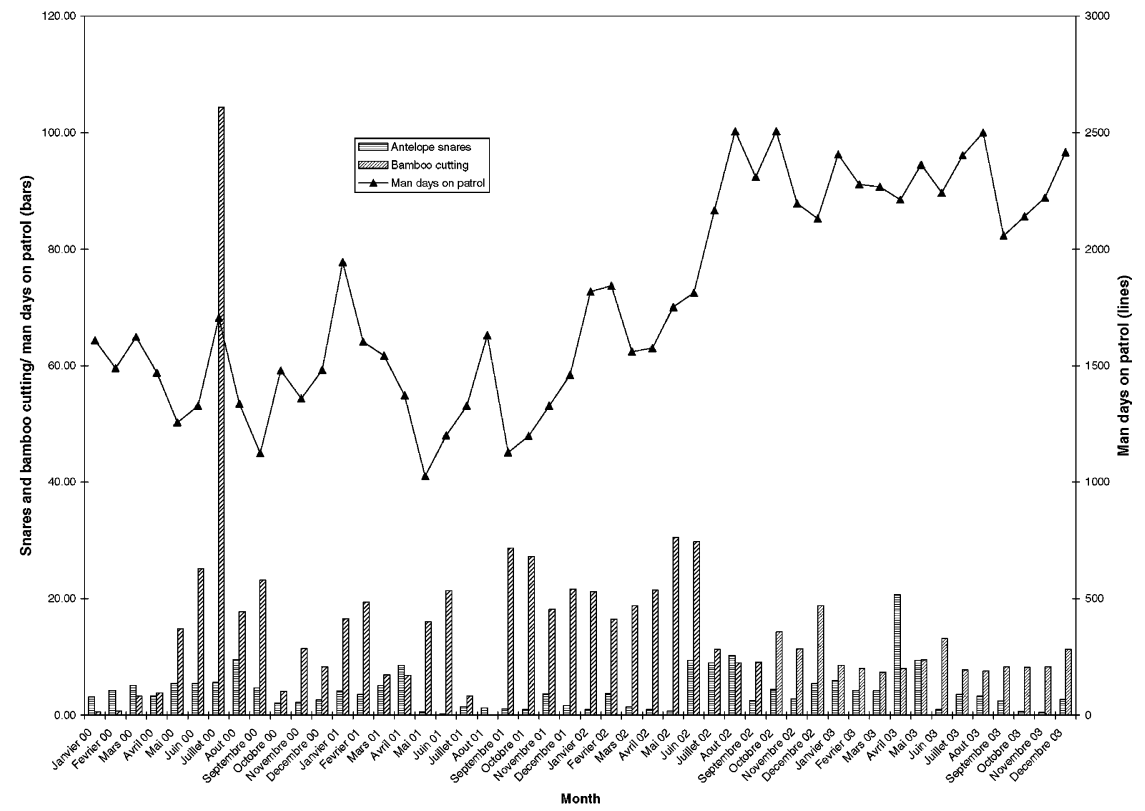

Figure 5. Number of observations of antelope snares and bamboo cutting per man days on patrol (bars), and effort (line; number of man days on patrol) in the Virunga Massif, 2000-2003. 


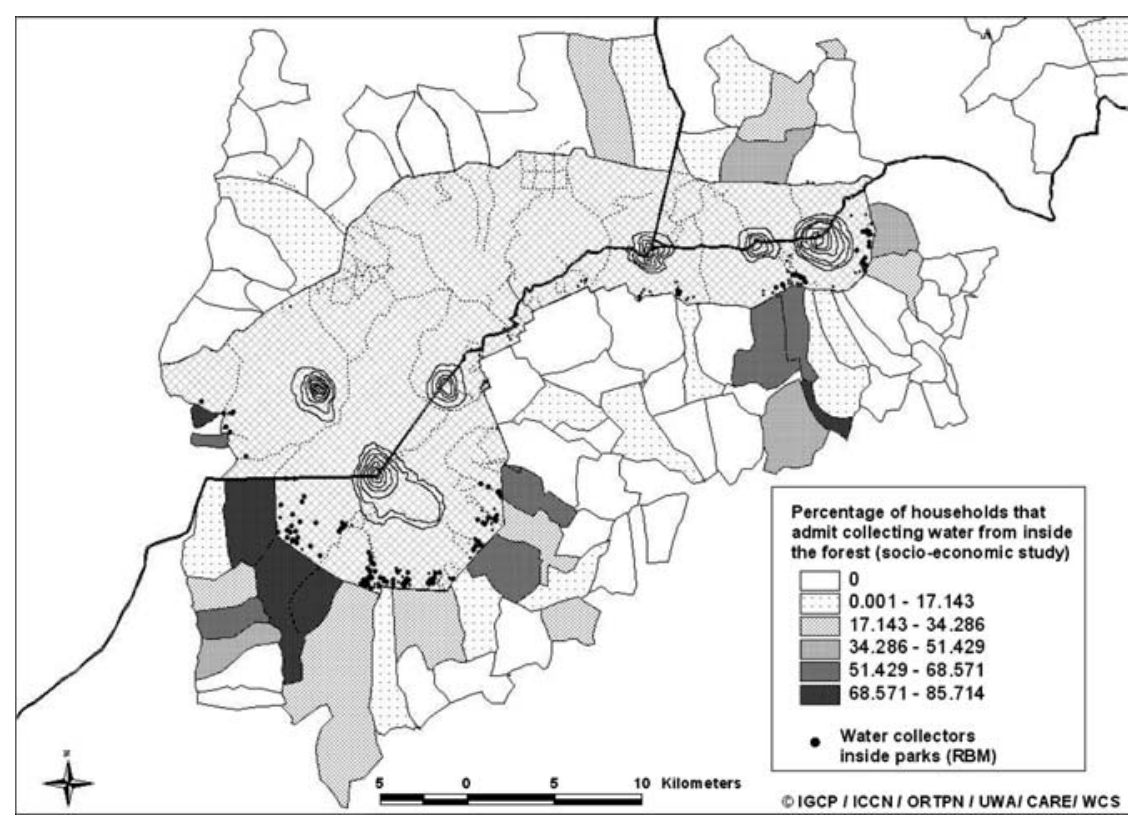

Figure 6. Comparison of ranger based monitoring data on the location of water collecting inside the forest of the Virunga Massif with the levels of dependency of the community outside the forest on collecting water from inside (socio-economic data from Plumptre et al. 2004).

and monitoring function in difficult border areas. Often an event on one side of the border will impact on resources and people in other areas on the other side of the border. An example includes the deforestation for security reasons of the Mwaro corridor between the Mikeno and Nyamulagira Sectors of the Virunga National Park in DRC. These activities cut off the normal passage for elephants and buffalo in the park, thus causing an increase in crop raiding and human-wildlife conflict incidents in Uganda and Rwanda (Figure 9). Before clearing of the corridor there had been no reported incidences of crop raiding by elephants around PNV or Mgahinga Gorilla National Park (MGNP), but after clearing incidents were reported in DRC, Uganda and Rwanda. Communication between the wardens in three countries established that the crop raiding incidents took place after the corridor was cleared and elephants were no longer able to migrate through to the Nyamulagira sector of Virunga National Park.

\section{Discussion}

In this paper we have described a number of examples of data collected by the RBM programme which illustrate the potential value of the programme as a tool for conservation and protected area management. Monitoring is an 


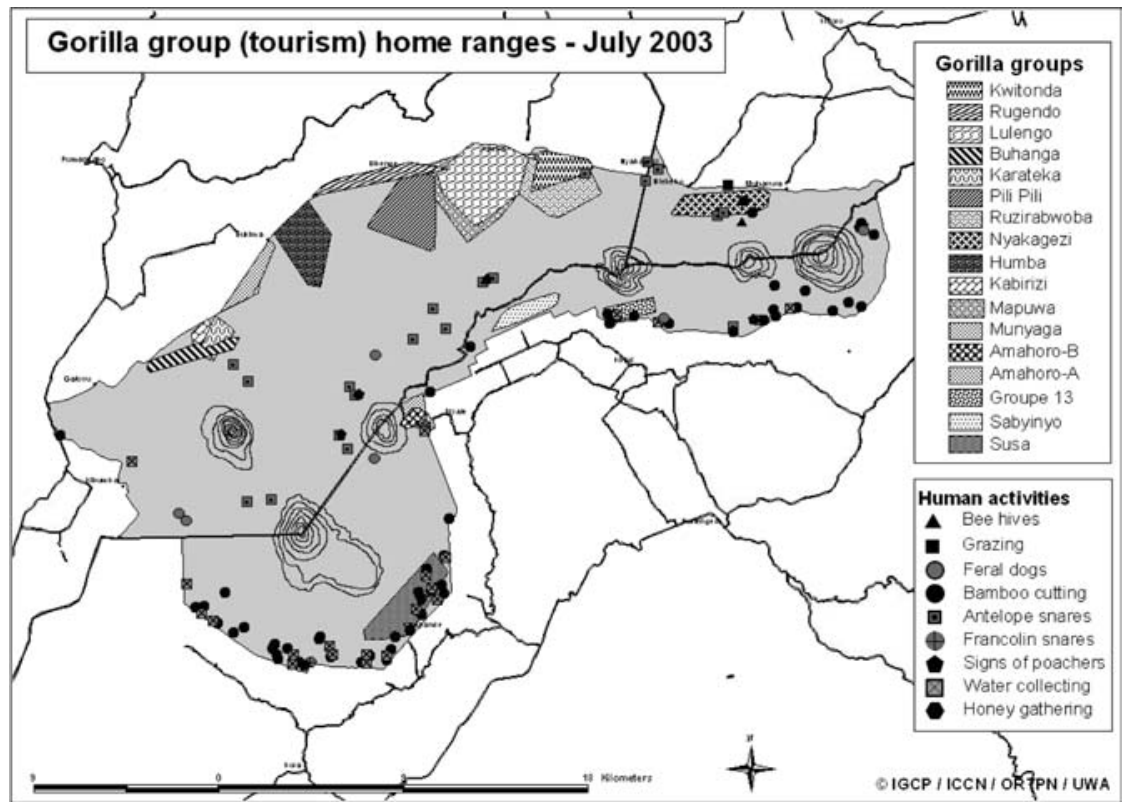

Figure 7. Gorilla group (tourism) monthly use home ranges and observations of illegal human activities in the Virunga Massif in July 2003.

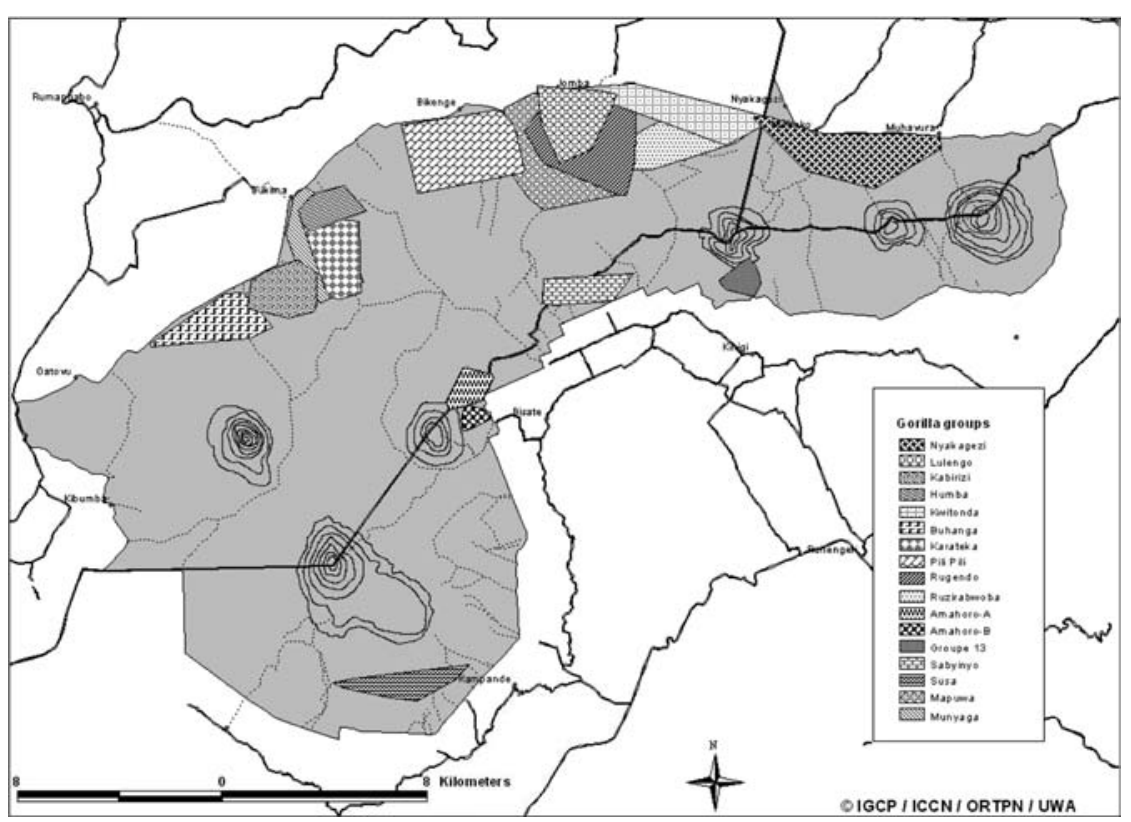

Figure 8. Gorilla group (tourism) monthly use home ranges in the Virunga Massif in September 2003. 
Table 2. Snare injuries in tourism gorilla groups in the Virunga-Bwindi Region before and after introduction of Ranger Based Monitoring (RBM).

\begin{tabular}{lcc}
$\begin{array}{l}\text { Number of snare injuries/amputation } \\
\text { in tourism gorilla groups }\end{array}$ & Pre RBM (ca. 15 years) & Post RBM (6 years) \\
\hline Susa & 3 & \\
Sabyinyo & 0 & \\
Group 13 & 3 & \\
Amahoro-A & 1 & 1 \\
Amahoro-B & 0 & 1 \\
Nyakagezi & 1 & \\
Kwitonda & 2 & \\
Mapuwa & 1 & \\
Lulengo & 2 & \\
Ruzirabwoba & 0 & \\
Rugendo & 0 & \\
Kabirizi & 1 & \\
Humba & 0 & \\
Munyaga & 0 & \\
Karateka & 0 & \\
Buhanga & 0 & \\
Pili Pili & 0 & \\
Karema & 1 & \\
Total & $\mathbf{1 5}$ & \\
\hline
\end{tabular}

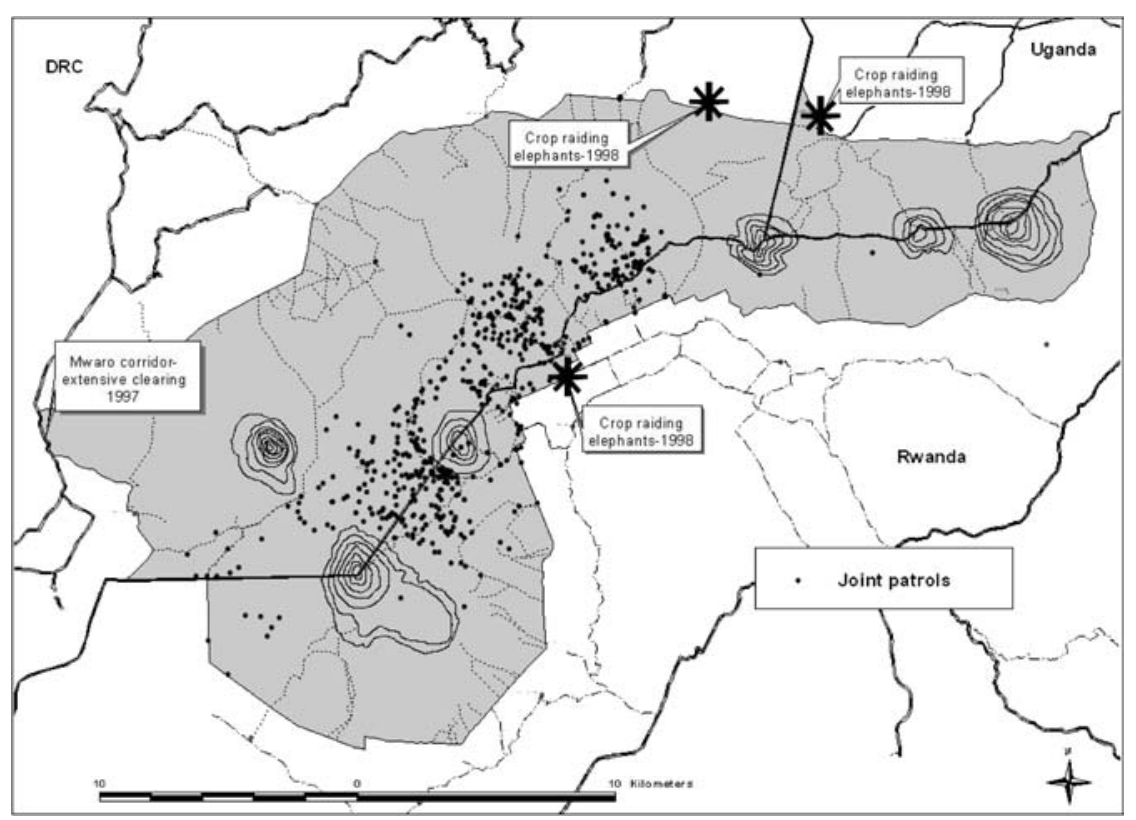

Figure 9. Location of joint Rwanda/Uganda/Democratic Republic of Congo ranger patrols (19982003) and reported human-wildlife conflict areas (crop raiding elephants) in the Virunga Massif. 
essential part of any project/protected area management as it allows an evaluation of the success of conservation activities and allows the protected area authorities to adapt their activities in the light of the results of the monitoring process (Margoluis and Salafsky 1998). Our results suggest that the RBM system can provide a basic yet useful tool for guiding protected area managers in their conservation strategies.

From a pilot project RBM has evolved into a system integrated into management structures of 4 parks in 3 countries. With its strong training component it has resulted in park staff being trained and more capacity being built resulting in empowerment of the protected area authorities. The training is being increasingly organized and carried out by the park staff themselves reducing their dependency on external support and contributing to the sustainability of the programme.

The programme looks at seasonal patterns in illegal activities, patterns through time and also the distribution of different illegal activities, helping guide park managers in making decisions on surveillance activities within the protected areas. Analysis of the results from the RBM programme show that observations of illegal activities within the Virunga Massif are high at all times, reflecting the pressure on the natural resources by the surrounding population. Although only reflecting the observations that were made in the areas patrolled, which may not be representative of the whole Massif, in these areas levels of illegal activities do not appear to be decreasing. The response to the high levels of illegal activities has been an increase in patrol effort between 1998 and 2003; however, this has not resulted in a decrease in illegal activities within the areas of the parks being patrolled.

RBM data collected inside the parks is being used together with socio-economic monitoring of conditions outside the parks to increase understanding of the need for resources by local populations, and the activities associated with the need for these resources (over space and time). This allows the 3 park authorities to understand the links between the human economic and social conditions with the illegal activities (threats) to the forest and wildlife. Using this information targeted activities are being developed to assist the populations in meeting their needs thus reducing pressure on the parks and the resources.

Information from the programme is also being used to plan tourist visits to the gorillas. Gorillas range over greater distances in the dry season in search of food, and the visit can be more physically demanding for both park staff and visitors. Gorilla groups can also cross into different countries and this needs to be taken into account when planning visits.

Before the monitoring programme was established, information on the gorillas was confined to those groups being studied around the Karisoke Research Center, a small area of the Virunga Massif. Using the information from RBM we are able to gain an insight into a much wider proportion of the total population. The information from RBM was used together with information on known gorilla groups to provide an estimate of the gorilla population in 
2000, when it was not secure enough to carry out a full census (Kalpers et al. 2003). RBM results have been used to identify interesting topics for future research; including gorillas leaving the forest and raiding crops in the adjacent fields, gorillas de-barking eucalyptus trees, habitat utilization and feeding ecology. Questions on population dynamics can also be addressed including rates of transfer (emigration and immigration) between groups, birth and death rates.

RBM and other joint field activities are the cornerstone of the regional vision developed by IGCP since 1991. The philosophy of this vision is to encourage a bottom-up approach where field staff and park wardens build strong links across the international borders, based on their most immediate management needs. Participation by park staff in regular regional meetings to discuss issues related to ranger based monitoring has increased communication and collaboration between the park staff in the three countries.

\section{Challenges to the ranger based monitoring and solutions}

Ranger based monitoring in these Parks faces a number of challenges, including regional insecurity, institutional weakness within the parks authorities, the limitations of an opportunistic system, and the pressure to turn the programme into a 'high tech' system.

The Great Lakes Region has been the scene of a number of conflicts during the past 10 years which have affected security and the ability of park authorities to effectively manage their parks. The IGCP has continued to work in these areas by primarily supporting the park authorities to carry out conservation activities. IGCP's approach is flexible and adapts to the dynamic political and economic situation in the region. Given the fact that the RBM programme utilises low levels of technology, is adaptive and does not rely on external support, data has continued to be collected during times of instability in the region, providing information to park management through periods of war and political unrest.

Another obstacle that the programme is facing is the institutional weakness of the protected area authorities, some of whom have been deeply impacted by the last 15 years of political unrest in the region. IGCP's holistic regional approach is tackling the issue of institutional weakness of the park authorities, by working with them on a number of different programmes, supporting tourism development, policy development, community conservation, enterprise development, and institutional strengthening, in addition to the RBM programme (Rainer et al. 2003).

There are limitations associated with an opportunistic system, which relies on ranger patrols to collect data, and the results generated will never comply with rigorous scientific sampling (but see Brashares and Sam 2005 (this issue)). The system relies on data collected by patrol rangers whose primary focus is law enforcement not monitoring; and who patrol as conditions allow. There is 
a danger that rangers are only patrolling in areas where they find illegal activities so that the data may be biased towards these sites, patrol rangers can also become bored with collecting data over time which may then be reflected as a reduction in levels of illegal activities. The system does not take into account differences in observer reliability, and whether detection of observations changes in different habitats. However, it is important for protected area management that the information needs of the park authorities and the level of resources available are considered and data collection is conducted in this context. The current RBM system is simple, utilizes low technology and uses a low level of resources. Increasing the technology and the resources could lead to a more scientifically rigorous system; however, maintaining a high tech system could then itself become a greater challenge.

\section{Sustainability}

The basis of the RBM programme has always been the 'training of trainers', and the programme has at all times emphasized working with the protected area authorities on the ground - the wardens, rangers and guards who are responsible for management of the parks. RBM is also a strong tool for capacity building and the result of this approach has been enormous support for and interest in the programme, as park personnel are able to see the results of the programme and use them as a basis for making informed management decisions. This approach has also meant that having been trained, the RBM supervisors have become largely autonomous and have organized full monitoring training sessions for the field teams in their respective protected areas. Due to this autonomy, even in times of uncertain security, the programme and training will be able to continue, as has been demonstrated in the past years, and that information will continue to be made available for the protected area authorities. The programme empowers rangers and trackers in data collection, a task that is not normally asked of them. In return there is a positive impact on their motivation and hence the quality of the patrolling, tracking and guiding. By providing the field staff feedback and by giving them the opportunity to visualize the results of their work (maps, tables, illustration of trends over time), there is also the potential to increase their interest in park management.

\section{Costs}

The costs in terms of human resources include the patrol rangers, gorilla trackers and guides who collect the data, and the time of the senior staff who analyse the data and attend meetings and training sessions. Currently the estimated cost of the programme in the Virunga Massif amounts to USD 126/ $\mathrm{km}^{2} / \mathrm{yr}$. Twenty percent of this figure (USD $22 / \mathrm{km}^{2} / \mathrm{yr}$ ) is covered by the 
protected area authorities (salaries of patrol rangers), while the remaining $80 \%$ is met by IGCP (including programme staff time and operating costs, the provision of equipment, and training and meetings). In Rwanda and Uganda the human resource costs (staff salaries) are completely covered by the park authorities, while in DRC staff allowances are paid by partner organizations. In Uganda some equipment is provided by different partner organizations, while in Rwanda and DRC, IGCP currently provides equipment and also a low level of funding for consumables (including stationery and photocopying). However, as the situation in each of the three countries stabilizes it is anticipated that the protected area authorities will take over financial support of the programme.

Although this cost may seem high compared to the funds available for protected area management in many parts of Africa (Culverwell 1997), it must be remembered that the Virunga Massif is home to the mountain gorilla, which attracts international attention and has the potential to generate over 13 million dollars per annum in revenue from tourism (Hatfield 2003). Staff numbers are high to ensure protection of this endangered animal and its habitat. The global average of park field staff per $1000 \mathrm{~km}^{2}$ is 27 (James et al. 1999), while in the Virunga Massif there are 266 field staff per $1,000 \mathrm{~km}^{2}$ - approximately ten times the global average. Thus the large number of staff in the Massif is reflected in the cost per $\mathrm{km}^{2}$ of the monitoring programme.

\section{Efficiency}

In pursuing efficiency the aim is to get the most information out of the simplest system (the one that consumes the least resources, such as funds, energy and human resources). The RBM programme is efficient in that it provides information that is timely, directly related to management concerns, the costs are minimal and the data is collected in a systematic and organized way. The information that is provided can be easily fed into analysis systems/processes and can be quickly processed and distributed, both at a national and a regional level. The system can be relatively easily institutionalized in other protected areas, both within Africa and further a-field. Low technology methods can in principle be adapted to any site. If toponyms can not be used a grid system or another simple location method can be designed.

\section{Community involvement in monitoring}

An approach that is being increasingly considered for monitoring biodiversity in developing countries is the participation of local communities in monitoring and management of natural resources. The strength of participatory monitoring lies in reinforcing local management of the land and resources, and dealing with threats to biodiversity (Danielsen et al. 2003). Ranger based 
monitoring has its limitations in terms of involving the communities in data collection in the forest, given the fact that the official mandate of park protection is assigned to parastatals in the 3 countries. However, given the importance of monitoring the socio-economic conditions in the communities adjacent to the parks, the next step in the RBM programme is the identification of socio-economic parameters for communities and local government institutions to monitor. Parameters will be identified and community members trained to collect the data, which will then be combined with the in-park ranger patrol data to give a more complete picture of the situation in and around the mountain gorilla parks. This approach has the potential to improve communication between local communities and park authorities, increase the information available to the park managers and thus further strengthen the management of the park.

\section{Acknowledgements}

This paper is an expanded version of a presentation we were invited to make at a symposium on locally-based monitoring held in Denmark in April 2004 (www.monitoringmatters.org). The symposium was organized by the Nordic Agency for Development and Ecology (NORDECO, Denmark), and the Zoology Department of Cambridge University (UK). Funding from NORDECO enabled MG to attend the symposium. The authors wish to thank the protected area authorities of the three countries where ranger-based monitoring has been setup, namely the Rwanda Office for Tourism and National Parks, the Congolese Institute for Nature Conservation and Uganda Wildlife Authority. The development of the programme was made possible thanks to the financial support of the Wildlife Conservation Society, the United Nations High Commission for Refugees, CARE-International and the US Fish and Wildlife Service, with technical input provided by Dian Fossey Gorilla Fund International (Karisoke Research Center), Mountain Gorilla Veterinary Project, Institute of Tropical Forest Conservation and World Wide Fund for Nature International. In Uganda the scheme has been developed in collaboration with the German Cooperation (GTZ) and Uganda Wildlife Authority. The authors also wish to thank N. Burgess, F. Danielsen, J. Brashares, A. Balmford and an anonymous reviewer for their suggestions and comments on the early versions of the manuscript.

\section{References}

Brashares J.S. and Sam M.K. 2005. How much is enough? Estimating the minimum sampling required for effective monitoring of African reserves Biodivers. Conserv. 14: 2709-2722.

Brooks T., Balmford A., Burgess N., Fjeldså J., Hansen L.A., Moore J., Rahbek C. and Williams P. 2001. Towards a blueprint for conservation in Africa. BioScience 54: 613-624. 
Culverwell J. 1997. Long-term recurrent costs of protected area management in Cameroon. Monitoring of Protected Areas, Donor Assistance and External Financing, Ecological and Management Priorities of Current and Potential Protected Area System. Project 33.06.01. WWF, Yaoundé, Cameroon.

Danielsen F., Mendoza M.M., Alviola P., Balete D.S., Enghoff M., Poulsen M.K. and Jensen A.E. 2003. Biodiversity monitoring in developing countries: what are we trying to achieve? Oryx 37 : 407-409.

Hamilton L.S. 1996. The role of protected areas in sustainable mountain development. Parks 6: 213.

Hatfield R. 2003. Total Economic Value of the Virunga and Bwindi Forest Parks (BINP, MGNP, PNV, PNVi-sud). Internal Report for the International Gorilla Conservation Programme. International Gorilla Conservation Programme, Kigali, Rwanda.

IGCP 1996. Environmental Sector Profile: Strategic Action Plan for the Great Lakes Region. UNEP Report. UNEP, Nairobi, Kenya.

James A., Green M. and Paine J. 1999. A Global Review of Protected Area Budgets and Staffing. WCMC Biodiversity Series 10. World Conservation Union, Cambridge, UK.

Kalpers J., Williamson E.A., Robbins M.M., McNeilage A., Ndakasi L., Nzamurambaho A. and Mugiri G. 2003. Gorillas in the crossfire: population dynamics of the Virunga mountain gorillas over the past three decades. Oryx 37: 326-337.

Lanjouw A., Kayitare A., Rainer H., Rutagarama E., Sivha M., Asuma S. and Kalpers J. 2001. Beyond Boundaries: Transboundary Natural Resource Management for Mountain Gorillas in the Virunga-Bwindi Region. Biodiversity Support Program, Washington, DC, USA.

Liebenberg L. 2003. A New Environmental Monitoring Methodology. www.cybertracker.co.za/ Methodology.html. 2003.

Margoluis R. and Salafsky N. 1998. Measures of Success: A Systematic Approach to Designing, Managing and Monitoring Community-Oriented Conservation Projects. Biodiversity Support Program Adaptive Management Series, Washington, DC, USA.

Plumptre A.J., Behangana M., Davenport T.R.B., Kahindo C., Kityo R., Ndomba E., Nkuutu D., Owiunji I., Ssegawa P. and Eliu G. 2003. The biodiversity of the Albertine Rift. Albertine Rift Technical Reports 3. Wildlife Conservation Society, Kampala, Uganda.

Plumptre A.J., Kayitare A., Rainer H., Gray M., Munanura I., Barakabuye N., Asuma S., Sivha M. and Namara A. 2004. The Socio-Economic Status of People Living near Protected Areas in the Central Albertine Rift. Albertine Rift Technical Reports 4, Wildlife Conservation Society, New York, USA, 135 pp.

Rainer H., Asuma S., Gray M., Kalpers J., Kayitare A., Rutagarama E., Sivha M. and Lanjouw A. 2003. Regional Conservation in the Virunga-Bwindi Region: The Impact of Transfrontier Collaboration Through the Experiences of the International Gorilla Conservation Programme. J. Sustain. Forestry 17: 189-204.

Sheil D. 2001. Conservation and biodiversity monitoring in the tropics: realities, priorities, and distractions. Conserv. Biol. 15: 1179-1182.

Waller D. 1996. Rwanda: Which Way Now? An Oxfam Country Profile. Oxfam, Oxford, UK.

Weber W. 1987. Ruhengeri and its Resources: An Environmental Profile of the Ruhengeri Prefecture, Rwanda. Ruhengeri Resources Analysis and Management (PRAM) Project. Ruhengeri, Rwanda. 